\section{Primer migrates online}

The News Manual Online, by David Ingram and Peter Henshall, with illustrations by Bob Browne. www.thenewsmanual.net

$\mathrm{A}_{\text {primer that has trained many }}^{\mathrm{N} \text { IMPORTANT journalism }}$ Pacific journalists has finally migrated online, ensuring it a wider audience and a longer life. The trio of books dubbed The News Manual, which grew out of a search in the mid-1980s for resources for University of Papua New Guinea students, were published in 1991 with backing from the United Nations Educational, Scientific and Cultural Organisation (UNESCO).

A thorough and clear guide to basic reporting skills, including ethics, the law, and English grammar, their 700 pages formed an important resource in a region where only a lucky few got tertiary training, let alone specialised journalism coaching, and were (and still are) often plucked from a short secondary school career and thrown in the deep end.

The updated online version bills itself as a 'straightforward, no-nonsense guide' for journalists in developing countries - it has a Commonwealth bias, reflecting the authors' teaching experience-but it is just as relevant to journalism newbies in more developed societies.
So much of learning the craft of journalism is about marrying technical skills with common sense, nimble thinking and people skills, and the resource reflects this in a way a lot of developed-country textbooks don't (but should).

The beauty of The News Manual Online is that in its friendly, straightforward tone and content it makes no assumptions about what readers know. Journalism texts do need to discuss the telephone manner that gets results, how to break the ice with strangers in a natural way, and how to accurately calculate the numbers of people in a crowd, all areas covered by The News Manual Online.

The chapters give simple, clear examples in explaining concepts such as news sense. This is how it describes the need to make every intro word earn its keep:

Your intro is like a canoe being paddled against a fast flowing current. Every word in the sentence should be like a man with a paddle, helping to push the sentence forward. There is no room for lazy words sitting back without paddles in their hands. They just make work harder for the rest of the words. So look closely at every word and ask yourself: 'Does it have a paddle in its hand?' If it doesn't, throw it overboard!

Some of the fattest and laziest words to be found in the intro canoes 
are titles. Inexperienced journalists often think that they have to put full titles in the intro when, in fact, they belong later in the story.

Try to shorten titles for your intros wherever possible.

Exercises offer practice in intro writing and news story structure. The News Manual Online also discusses important issues for all reporters such as the dangers of stereotyping, the need to protect victims, and gender-neutral language. It looks at tricky issues such as the impact of tradition, culture and outside pressure, personal beliefs and reporting. It also asks questions media everywhere still struggle with — such as whether the families of public figures should be fair game for media.

There are useful links and resources and a public feedback page. Most importantly, the website is easy to navigate and uncluttered so those with sluggish internet can make the most of it. - Julie Middleton is an Auckland journalist and a former advocacy and communication officer for the Human Development Programme, Secretariat of the Pacific Community, Noumea.
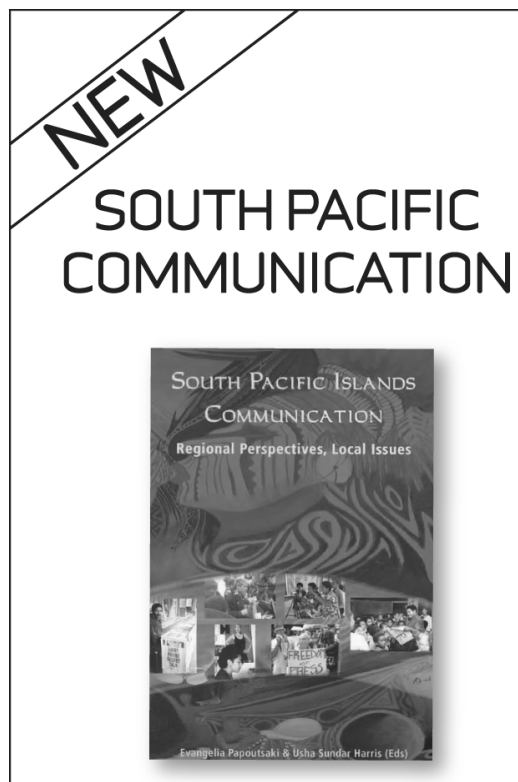

South Pacific Islands Communication: Regional Perspectives, Local lssues

Edited by Evangelia Papoutsaki and Usha Sundar Harris

Significant new scholarly contributions on communication issues by journalists and researchers working around the region.

Published by the Asian Media, Information and Communication Centre (Singapore), University of the South Pacific (Fiji) and the Pacific Media Centre.

PACIFIC MEDIA CENTRE AUTUNIVERSITY

Order from South Pacific Books Ltd www.sthpac.netstep.co.nz

sales 国southpacificbooks.co.nz Content details 回:

www.pmc.aut.ac.nz/publications.html Price: NZ\$50

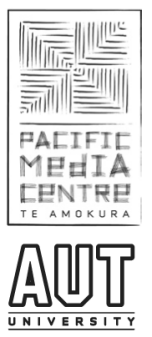

